\title{
Entegre Raporlama ile ilgili Yapılan Çalışmalar: Literatür Çalıșması
}

\author{
Mahmut ÇELEBİER ${ }^{1}$ \\ Fikret ÇANKAYA ${ }^{2}$
}

Öz: Dünyada entegre rapor yayınlayan işletmeler olmasına ve raporların hazırlanması için işletmelere yönelik bir entegre raporlama çerçevesi yayınlanmış olmasına rağmen işletmelere kllavuzluk edecek veya ana hatlart ortaya koyacak standart bir entegre rapor modeline ulaşılamamıştır. Çalışmanın temel amacı geçmişte yapılan entegre rapor çalışmalarını ortaya koyarak mevcut durumu görmek ve bu çalışmalardaki eksiklikleri belirleyerek literatürün sistematik bir şekilde incelemesini yapmaktır. Ayrıca, entegre raporun ne ölçüde faydalı olduğu tartışılmaktadır. Çalışmada, entegre raporlama ile ilgili yapılan çalışmalar esas alınan yönteme ve esas alınan konulara göre iki temel grup altında incelenmiştir. İncelemeler sonucunda mevcut çalışmalardaki eksikliklerin ortaya çıkarılması amaçlanarak gelecekte yapılacak çalışmalarda bu eksikliklerin giderilmesinde yönlendirici olmak hedeflenmiştir. Çalışmada elde edilen veriler ışığında 24 araştırmayla en çok çalışma esas alınan yöntem grubundan olduğu görülmektedir.

Anahtar Kelimeler: Entegre Raporlama, Değer Yaratma, Performans Raporlamasl, Bütünleşik Raporlama

Jel Kodlarl: M40, Q50, Q56

\section{The Papers on Integrated Reporting: A Literature Review}

ABSTRACT: Although an integrated reporting framework intended for enterprises has been published, a standard integrated reporting model has not been achieved to guide or outline enterprises. Therefore, the main purpose of this paper is to summarize the studies and to reveal the deficiencies in the past and to make a systematic review of the literature in order to contribute to the future. Furthermore, it is being discussed that to what extent an integrated reporting is beneficial. This paper, studies on integrated reporting have been analyzed under 2 groups, and these run as follows: based on the method and based on the issue. As a result of investigate, it is aimed to reveal the deficiencies in the current studies and to be a guide in eliminating these deficiencies in future studies. In the light of data obtained in the paper, it is seen that the most research is the based on the method with 24 studies.

Keywords: Integrated Reporting, Value Creation, Performance Reporting, Jel Codes: M40, Q50, Q56

\footnotetext{
1 Öğr. Gör. Mahmut ÇELEBİER, Amasya Üniversitesi, Yüksel Akın Meslek Yüksekokulu, celebier.m@yahoo.com, orcid.org/0000-0002-6684-667X

2 Prof. Dr. Fikret ÇANKAYA, Karadeniz Teknik Üniversitesi, İIBF, cankayaf@yahoo.com, orcid.org/0000-0002-0738-3580
} 


\section{Giriş}

Sanayileşme ve teknolojinin hızlı bir gelişim gösterdiği günümüzde işletmeler kâr amacı gütmenin yanı sıra, toplumda refah ve barışı artırmak gibi sosyal ve çevresel alanlarda da sorumluluk sahibi olmaya başlamışlardır. İşletmeler sorumluluklarını yerine getirmeleri halinde ve sorumlulukları ile ilgili gelecek stratejilerini şeffaf ve açık bir şekilde tüm menfaat sahiplerine duyurabilmek adına sosyal sorumluluk raporları hazırlamışlardır. Ancak, günümüze kadar hazırlanan sosyal sorumluluk raporları söz konusu işletme hakkında finansal ve finansal olmayan bilgileri menfaat sahiplerine ayrı ayrı raporlarda sunmaktadırlar. Hızla gelişen ve büyüyen ekonomi ile birlikte işletmelerin finansal bilgileri ile finansal olmayan bilgilerini ayrı ayrı sunması menfaat sahipleri için yeterli olmamaktadır. Bu sebeple, çalışmanın da konusunu oluşturan yeni bir sosyal sorumluluk raporu kavramı ortaya çıkmış ve entegre raporlama olarak adlandırılmıştır.

İşletmeler finansal olmayan bilgilerini de açıklayarak faaliyetlerinin şeffaflığını gözler önüne sererken aynı zamanda çevre ve toplum üzerindeki etkilerini de belirtmiş olacaklardır. Aynı zamanda yatırımcılara, kredi verenlere ve tüm menfaat sahiplerine doğru ve güvenilir bilgi verilerek işletmenin değer yaratmasına katkı sağlanacaktır. Özellikle önceki yıllarda işletmeler açısından kısa vadeli kazanımlar, uzun vadeli değer yaratma üzerinde önceliğe sahip olma düşüncesinin günümüzde değiştiği görülmektedir. Çünkü yeni raporlama yaklaşımı olan entegre raporlama ile işletmeler hem finansal hem de finansal olmayan bilgilerini açıklarken yalnızca geçmişe yönelik değil aynı zamanda geleceğe yönelik risk ve firsatları, yönetim yaklaşımlarını ve stratejilerini de açıklayacaklar ve tüm menfaat sahipleri ile aradaki güvensizliği en aza indirmeye çalışacaklardır.

Özetle entegre raporlarda, yatırımcıların ve tüm paydaşların kullanımı için geliştirilmiş ve tüm paydaşların işletmelerin finansal ve finansal olmayan bilgileri hakkındaki raporlara tek bir bütün halinde bakması ve strateji, yönetişim, risk, finansal ve finansal olmayan performanslar arasındaki bağları, kısa, orta ve uzun vadede yaratılan değerler ile birlikte sağlanması hedeflenmiştir. Bu doğrultuda entegre raporlamanın, menfaat sahipleri için geleceğe yönelik tahminlerinde yardımcı olabilecek en net bilgi unsuru olması kaçınılmaz olacaktır. Bu çalışmada ilk olarak entegre raporlama ile ilgili genel bilgiler verilecek ve devamında ise entegre raporlama ile ilgili yapılan akademik çalışmalar konulara göre farklı grup başlıkları altında yapılan sınıflandırma çerçevesinde kısa bilgiler verilecektir. Sonuç bölümünde ise gelecekteki çalışmalarda giderilmesi amacıyla söz konusu çalışmalardaki eksiklikler vurgulanmıştır.

\section{Entegre Raporlama ile ilgili Genel Bilgiler}

Güney Afrika Entegre Raporlama Konseyi (King III-IRCoSA) ile Uluslararası Entegre Raporlama Konseyi (IIRC) entegre raporlama kavramına öncülük eden entegre raporlama konusunda düzenlemeler ve standartlar geliştiren iki temel organizasyondur (Abeysekera, 2013: 229). Söz konusu organizasyonlardan Güney 
Afrika Entegre Raporlama Konseyi entegre raporlamayı, işletmenin hem ekonomik hem de sürdürülebilirlik performansının bir bütün halinde menfaat sahiplerine sunulması şeklinde tanımlarken (IRCSA, 2009: 91), Uluslararası Entegre Raporlama Konseyi (IIRC) (2013: 7) ise bir kuruluşun stratejisini, kurumsal yönetimini, performansını ve beklentilerini, kısa, orta ve uzun vadede değer yaratmayı nasıl sağlayacağını kısa ve öz bir şekilde bildirmesi olarak tanımlamaktadır. Küresel Raporlama Girişimi (GRI) ise entegre raporlamayı, bir kuruluş stratejisinin, yönetişiminin, performansının ve beklentilerin zaman içerisinde değer yaratmayı nasıl sağladığına dair menfaat sahipleri ile kurduğu bir iletişim aracı olarak ifade etmektedir (GRI, 2014: 85).

Yukarıdaki tanımlara ilaveten genel anlamda entegre raporlama, yatırımcıların ve tüm paydaşların kullanımı için işletmeler, finansal ve finansal olmayan bilgileri tek bir bütün halinde ve strateji, yönetişim, risk, finansal ve finansal olmayan performanslar arasındaki bağları kısa, orta ve uzun vadede yaratılan değerler ile birlikte sağlayan raporlar olarak tanımlanabilir (Eccles ve Saltzman, 2011: 59). Diğer bir ifade ile entegre raporlama, işletmenin geçmişe ait finansal ve finansal olmayan bilgilerinin aynı zamanda gelecekteki etkisini de göstermesini hedef alan bir raporlama türüdür.

Entegre raporlama ile diğer kurumsal raporlamalar arasında birtakım farklılıklar bulunmaktadır. Entegre raporun temel amacı, finansal sermaye sağlayan taraflara, kuruluşun zaman içerisinde nasıl değer yaratacağını açıklamaktadır. Dolayısıyla bir entegre rapor hem finansal hem de finansal olmayan diğer konular ile ilgili bilgiler içermektedir (IIRC, 2013a: 7). Ayrıca entegre raporlama, finansal sermaye sağlayan taraflara sunulan belgelerin kalitesini artırmayı, kurumsal raporlamaya daha bütüncül ve verimli bir yaklaşım getirmeyi, sermayenin geniş tabanı (finansal sermaye, üretilmiş sermaye, fikri sermaye, insan sermayesi, sosyal ve ilişkisel sermaye ile doğal sermaye) için hesap verebilirlik ve yönetilebilirlik öğelerini güçlendirmeyi amaçlamaktadır (IIRC, 2013: 2). Entegre raporlama hazırlayan işletmeler, kâr elde etme ve nakit akışını esas alan bir performansın ötesinde, toplumun tümünün ihtiyaçlarını (çevreyi koruma, toplumsal faaliyetler vb.) göz önüne alarak ve bu vizyonu tüm paydaşlara doğru bir şekilde aktararak kendi imajını yaratabilir ve geliştirebilir (Lapteş ve Sofian, 2016: 240).

2000’li y1lların başlarından günümüze kadar gerek kamu gerekse özel kuruluşlar için ulusal ve uluslararası standart belirleyiciler ve diğer kuruluşlar tarafindan çok sayıda kurumsal sosyal sorumluluk, sürdürülebilirlik ve çevresel, sosyal ve yönetişim (Environmental, Social and Govermant - ESG) standartları ve yönergelerinin dünya çapında yayımlanması için girişimlerde bulunulmuştur. $\mathrm{Bu}$ girişimlerin en sonuncusu olan entegre raporlama, yeni bir kurumsal sosyal raporlama yaklaşımı olarak görülmeye başlanmıştır (Katsikas ve diğerleri, 2016: 65). Bu bağlamda entegre raporlama uygulanması adına Nisan 2013 yılında küresel çapta kabul gören "Uluslararası Entegre Raporlama Çerçevesi” yayımlanmıştır. Bu çerçevenin amacı ise bir entegre rapor hazırlayan işletmelere raporun içeriğini 
oluşturan kılavuz ilkeler ve içerik öğelerini açiklayarak ve işletmelere yol göstermek ve temel kavramları belirtmektir (IIRC, 2013a: 4). Ayrıca çerçeve, işletmelerin değer yaratma konusunda kullanmak üzere entegre rapora dahil edilecek bilgileri açıklamaktır. Entegre rapor kâr amacı güden işletmelere yönelik hazırlanması amaçlanmış olsa da kâr amacı gütmeyen kuruluşlar tarafından da kullanılabilir niteliktedir. IIRC çerçevesi, farklı işletmelerin kendilerine özgü koşullar arasındaki farklılıklar üzerine odaklanarak ilgili bilgilere duyulan ihtiyacı karşılamada işletmeler arasında karşılaştırılabilirlik seviyesi oluşturmak amacıyla ilkelere dayalı olarak hazırlanmıştır (IIRC, 2013a: 7). IIRC çerçevesi ilkelere dayalı yaklaşım olması sebebiyle bir işletmenin IIRC çerçevesine uyup uyumadığının ve uyum derecesinin belirlenmesi zor olduğundan dolayı entegre raporun düzenlenmesi ve hazırlanması oldukça zordur (DeVilliers ve diğerleri, 2016: 3). Tablo 1'de entegre raporun hazırlanmasinda temel olarak kullanılacak olan kılavuz ilkeler ve içerik öğeleri yer almaktadır (IIRC, 2013a: 5).

Tablo 1: Entegre Raporlama Kılavuz İlkeler ve İçerik Öğeleri

\begin{tabular}{ll}
\hline \multicolumn{1}{c}{ Kılavuz Illkeler } & \multicolumn{1}{c}{ İçerik Ö̈̆geleri } \\
\hline $\begin{array}{l}\text { Stratejik odak ve geleceğe } \\
\text { yönelim }\end{array}$ & $\begin{array}{l}\text { Kurumsal genel görünüm ve } \\
\text { diş çevre }\end{array}$ \\
\hline Bilgiler arası bağlant1 & Kurumsal yönetim \\
\hline Paydaşlarla ilişkiler & İş modeli \\
\hline Önemlilik & Riskler ve firsatlar \\
\hline K1sa ve öz olma & Strateji ve kaynak aktarımı \\
\hline Tutarlılık ve karş1laştırılabilirlik & Genel görüş \\
\cline { 2 - 3 } & Hazırlık ve sunum temeli \\
\cline { 2 - 2 } & Genel raporlama ilkeleri \\
\hline
\end{tabular}

Kaynak: IIRC, 2013a: 5; Kaya vd., 2016: 88.

Türkiye' de entegre raporlama çalışmaları dünyadaki gelişime göre biraz daha yavaş ilerleme kaydetmektedir. Zira ilk olarak, IIRC iş birliği ile Sürdürülebilir Kalkınma Derneği ve Türkiye Kurumsal Yönetim Derneği (TKYD) önderliğinde Entegre Raporlama Platformu kurulmuştur (Topçu ve Korkmaz, 2015: 7). Daha sonra 2011 yılında Türkiye Kurumsal Yönetim Derneği (TKYD) ve Sürdürülebilir Kalkınma Derneği (SKD) tarafindan bir çalışma ortamı kurulmuş ve Türkiye'de entegre raporlama hakkında farkındalık ortaya koymak için çalışma başlatılmıştır. 2015 yılında ise TÜSİAD tarafından hazırlanan "Kurumsal Raporlamada Yeni Dönem: Entegre Raporlama" adlı Türkçe rehberi literatüre kazandırmıştır. Bu rehberin ve de entegre raporun tanıtılması amaciyla düzenlenen konferansin ardından ilgili taraflarca 2017 yılında Entegre Raporlama Türkiye Ağı (ERTA) kurulmuştur (ERTA, 2018).

Entegre raporun sağlamış olduğu faydalar her ne kadar işletme, sanayi ve ülkeye göre farklılıklar gösterebilse de genel olarak entegre raporun sağlamış olduğu faydalar üç grupta açıklanabilir. Bunlar (Eccles ve Armbrester, 2011: 15): 
- İçsel faydalar,

- Dişsal olarak ifade edilen piyasaya yönelik faydalar,

- Risklerin yönetime sağladığı faydalar.

İcsel faydalar;

- Performans ölçümü için kullanılan metrik ölçütler hakkında daha açık ve net bilgilerin belirlenmesi,

- Çevresel, sosyal ve yönetim performansların soyut bir şekilde ifade edilmesinden ötede finansal ve finansal olmayan performans arasındaki ilişkilerin daha açık ve somut olarak belirtilmesi,

- İşletmenin strateji ve hedeflerine çalışanlarda dahil olmak üzere daha bütünsel bir bakış açısı ile iç kontrol sisteminin daha da geliştirilmesi için eksikliklerin kolay tespit edilmesi,

- Risklere karşı daha iyi bir yönetim ile üretimdeki verimliliği artırarak, mevcut ve potansiyel çalışanlar ile paydaşlar ile daha iyi bir iletişim kurulması olarak açıklanabilir.

\section{Dışsal olarak ifade edilen piyasaya yönelik faydalar;}

- Yatırımcıların üzerinde durduğu sosyal sorumluluk ihtiyaçlarının gerçekleştirilmesi,

- Borsalarda oluşturulan sürdürülebilirlik endekslerine dahil olma, finansal analistlere ve veri sağlayanlara işletme ile ilgili finansal olmayan bilgileri de sağlamak,

- Sürdürülebilirliği satın alma kararlarında büyük rol oynayan bireysel tüketiciler ve ticari müşterilerin beklentilerini tatmin etme,

- Tedarikçilere karşı da işletme güvenilirliğini sağlayarak tedarik zincirinde oluşabilecek riskleri azaltmak,

- İşletmenin itibarını ve marka değerini artırmak ve tüm paydaşlar ile iyi iletişim kurarak itibar riskinin azaltılması, olarak açıklanabilir.

\section{Risklerin yönetime să̆ladı̆̆ faydalar ise;}

- Gerçekleşmesi muhtemel yeni mevzuatlara önceden hazırlıklı olarak yeni mevzuatlara hızlı bir şekilde yanıt vermek,

- Borsada gerçekleşen yeni düzenlemelere hemen ayak uydurmak ve yeni düzenlenecek olan çerçeveler ve standartlar geliştirildiğinde katkıda bulunmak olarak açıklanabilir. 


\section{Literatür Taraması}

Entegre raporlama, finansal olmayan raporlarda yer alan bilgilerle finansal raporlarda yer alan bilgilerin tek bir parçada sunumu anlamına gelmemektedir. Entegre raporlama, yatırımcıların ve tüm paydaşların kullanımı için işletmeler finansal ve finansal olmayan bilgiler hakkındaki raporlamalara tek bir bütün halinde bakmalı ve strateji, yönetişim, risk, finansal ve finansal olmayan performanslar arasındaki bağlar kısa, orta ve uzun vadede yaratılan değerler ile birlikte sunulmalıdır. Başka bir ifade ile işletmenin geçmiş finansal ve finansal olmayan bilgileriyle bunların gelecekteki etkileri belirtilmelidir. Gelecekteki etkiler düşünüldüğünde entegre raporlamanın önemini işletmeler fark etmeye başlamış ve günden güne popüler bir kavram olmaya başlamıştır. Söz konusu farkındalık sadece ișletmeler nezdinde değil akademik anlamda da önem kazanmıș ve özellikle 2014 yılından sonra yapılan ampirik çalışmalarda artışlar olmuştur. $\mathrm{Bu}$ nedenle bu çalışmanın temel amacı yapılan çalışmaları özetleyerek geçmişte yapılan eksiklikleri ortaya çıkarmak ve geleceğe katkı sağlaması açısından literatürün sistematik bir şekilde incelemesini yapmaktır.

Çalışmada entegre raporlama ile ilgili yapılan çalışmalar ortak özelliklerine göre farklı gruplara ayrılarak incelenmiştir. Söz konusu gruplar esas alınan yöntem ve esas alınan konulara göre iki temel grup altında sınıflandırılarak gösterilmiştir. Bu sınıflandırma yapılırken "entegre raporlama - integrated reporting, bütünleşik raporlama, tümleşik raporlama, performans - performance ve değer yaratma - value creation" anahtar sözcükleri ile ulusal ve uluslararası dergilerde $2011-2018$ yılları arasında yayınlan çalışmalar dikkate alınmıştır. İlgili tarihler boyunca yaklaşık 200 araştırma incelenmiş olup direkt konuyla ilgili olan 43 araştırma çalışma kapsamında ele alınmıştır. Bu araştırmaların \%67'si esas alınan yöntemi, \%33'ü ise esas alınan konuyu oluşturmaktadır. Belirlenen bu gruplandırma ile entegre raporlama ile ilgili mevcut araştırma sonuçlarının önemli yanlarını ve eksikliklerini vurgulayarak araştırmalardaki boşluklara başka bir bakış açısı sağlanması düşünülmektedir. Ek olarak bu çalışma hem literatüre entegre raporla ilgili yapılan çalışmaları tek çatı altında toplayarak etkilerini göstermesi hem de uygulayıcılar için entegre raporun yayınlanması konusundaki endişeleriyle ilgili farkındalıklarının artırılması için oldukça faydalı olacağı düşünülmektedir. $\mathrm{Bu}$ doğrultuda incelenen çalışmalar ve grupları aşağıda ifade edilmiştir.

\subsection{Esas Alınan Yönteme Göre Yapılan Çalışmalar}

Uzman, Yatırımcı ve İşletme Yöneticileri ile Yapılan Görüşmelere Dayanılarak Yapılan Çalışmalar

Entegre raporlama ile ilgili olarak işletme yöneticileri ve yatırımcılarla yapılan görüşmelere dayandırılarak yapılan çalışmalarda, entegre raporlamanın, yatırımcıların ihtiyaçlarını karşılamak, kurumsal meşruluğun artırılması, itibarın artırılması, raporlamadaki karmaşıklığı ve tutarsızlığ önlemek gibi nedenlerle 
yapıldığı ileri sürülmektedir (Stubbs ve diğerleri, 2014; Steyn, 2014; Higgins ve diğerleri, 2014).

Stubbs ve diğerleri (2014), Avusturyalı yatırımcılarla yaptıkları görüşmelerle, işletmeler tarafından sağlanan bilgilerle yatırımcıların ihtiyaç duydukları bilgiler arasında önemli bir boşluk olduğunu tespit etmiştir. Benzer bir başka çalışmada Higgins ve diğerleri (2014), 23 Avusturya işletme yöneticileri ile yaptıkları görüşmelerde, yöneticilerin entegre raporlamayı organizasyonel bir hesap verme aracı olarak değil, stratejik öykü ve beklentileri anlatma aracı olarak gördüklerini ifade etmiştir. Aynı şekilde, Güney Afrika'daki üst düzey yöneticilerinin entegre raporlamayı benimsemelerini, entegre raporlamaya olan bakış açılarını ve faydalarını tespit etmeye çalışan Steyn (2014), çalışmasının sonucunda entegre raporurn kurumsal meşruiyeti ve itibarı artırmak için benimsendiği sonucuna ulaşmıştır.

Öte yandan Atkins ve Maraoun (2015), Güney Afrika kurumsal yatırım endüstrisindeki 20 uzmanla görüşmeler yapmış ve görüşmeler sonucunda IIRC çerçevesinin geleneksel olarak düzenlenen yıllık raporların iyileştirilmesi ve geliştirilmesi olarak gözlemlemişlerdir.

Entegre raporlamanın ortaya çıkış nedenlerini araştırmak için Rowbottom ve Locke (2016) entegre raporlamanın dünya çapındaki temsilcileri ile görüşme gerçekleştirmişlerdir. $\mathrm{Bu}$ görüşmeler sonucunda, entegre raporlama paydaş beklentilerine karşılık vermek için ortaya çıktığını ve raporlama karmaşıklığ 1 , tutarsızlığı ile yatırımcılar için daha kabul edilebilir raporlama çerçevesi olması gerektiği sonucuna ulaşmıştır.

Yukarıda yer alan çalışmaların sonuçlarına göre, entegre raporlamayı kullanım amacının işletme kilit personellerinin, yöneticilerinin ve üst yöneticilerin tam olarak anlaşılmadığı bu yüzden de entegre raporlama uygulamalarının teorilerden biraz daha farklı bir amaç doğrultusunda kullanıldığı görülmektedir. Ayrıca yapılacak çalışmaların, yalnızca yatırımcı, uzman ve işletme yöneticileri ile değil aynı zamanda tüm paydaşları da (tedarik zincirleri, düzenleyiciler, standart belirleyiciler, sanayi ve meslek kuruluşları vb.) dahil edecek şekilde yapılması daha etkin ve verimli sonuçlar ortaya koyacaktır.

\section{İçerik Analizi Yapan Çalışmalar}

Entegre raporlama ile ilgili içerik analizi yapan çalışmaların bazıları olumlu gelişmeler olduğunu ileri sürerken (PWC, 2013; PWC, 2014), bazıları ise raporlarda tutarsızlıklar, kopukluklar olduğunu ve birçok çalışmanın entegre raporlamaya uygun olmadığını (Solomon ve Maroun, 2012; Deloitte 2014), diğer bazıları ise işletmelerin raporlamaya hazır olmadığını (PWC,2014c; Hao, 2014) ileri sürmektedir.

Entegre raporlamayla ilgili olumlu düşünce ileri süren çalışmalardan birinde PWC (2013), İsveç Stockholm Borsası OMXS30 endeksine kote olan işletmelerin yayımladıkları raporlar incelenmiş ve işletmelerinin büyük bir çoğunluğunun 
entegre raporlama konusunda iyi bir temel yapıya sahip oldukları tespit edilmiştir. Aynı kuruluşun İspanya Madrid Borsası'nda IBEX 35 (en likit 35 hisse senedi endeksi)' de yer alan işletmelerin yıllık raporlarını inceleyen bir diğer çalışmasında entegre raporlama hazırlama konusunda ilerleme kaydedildiğini tespit etmiştir (PWC 2014a). Benzer düşüncedeki çalışmalardan bir diğerinde Chersan (2015) uluslararası boyutta işletmelerin 2014 yılında yayınlamış olduğu entegre raporların içeriklerini analiz etmiştir. Analizler sonucunda entegre rapor sayısında artışın olduğunu ve açıklanan bilgiler arasında bağlantının daha da güçlendiğini vurgulamıştır.

Bir başka çalışmada ise PWC (2015), Malezya Borsası'nda en iyi 50 işletmenin kurumsal raporları incelenmiş ve çoğunluk olarak IIRC çerçevesi içerik öğelerine uygun olduğu tespit etmiştir. Benzer şekilde, Yüksel ve Aracı (2017b) daha spesifik bir araştırma yapmış ve bu araştırmalarında Uluslararası Entegre Raporlama Komitesi veri tabanında yer alan hizmet işletmelerine ait raporlarına içerik analizi uygulamıştır. Araştırmanın sonucunda ise işletmelerin yayınladıkları raporların IIRC Entegre Raporlama Çerçevesi'nde yer alan içerik öğeleri ile uyumlu olduğunu belirtmişlerdir. Çimento sektöründeki işletmelerin yayınladıkları raporların IIRC Entegre Raporlamaya uygunluğunu inceleyen Dereköy (2018), çimento sektöründeki işletmelerin yayınladıkları bilgilerin yüksek oranda çerçeveye uygun olduğunu fakat belirli bir standartları olmadığını ifade etmişlerdir. Ayrıca çimento sektöründeki işletmelerin en az bilgiyi sermaye özelliklerinde verdiklerini tespit etmiştir.

Surty ve diğerleri (2018) ise Güney Afrika'daki devlete ait 21 işletmeden 19 tanesinin 2013, 2014 ve 2015 mali dönemlerine ait entegre raporların niteliğini ve kapsamını KING III ve Entegre Raporlama Çerçevesine göre ne ölçüde yerine getirildiğini puan kartı hazırlayarak araştırmıştır. Çalışmanın sonucunda, 2013 yılında az bilgi sağlandığını ancak yıllar ilerledikçe paylaşılan bilgilerin arttığını ifade etmişlerdir. Ayrıca, üç yıl boyunca hiçbir işletmenin mükemmel düzeyde açıklama yapmadığını açıklanan bilgilerin ise tatmin edici olduğunu ve daha da geliştirilebilir olduklarını ifade etmişlerdir.

Yukarıdaki çalışmalarda yer alan ülkelerin entegre raporlamaya hazır oldukları görülse de hazır olmayan ülkeler de bulunmaktadır. Nitekim Havlova (2015) IIRC pilot programına 2012 yılından önce kayıtlı olan 48 işletme üzerinde yaptığı araştırmada tam bir şekilde entegre raporun hazırlanmasının beş y1lı bulduğunu tespit etmiştir. Ayrıca çalışmada kamu kuruluşlarının özel işletmelere göre entegre rapor hazırlamada personellerin daha isteksiz olduğunu ifade etmiştir. Kamu kuruluşlarının entegre rapor hazırlamasında isteksiz olmasına benzer bir sonuçta Chersan (2015)'te yaptığ 1 çalışmada ifade etmiş ve dünya üzerinde entegre rapor hazırlayan işletmelerin \%90'ınını özel işletmelerin oluşturduğunu açıklamıştır.

Aynı şekilde Solomon ve Maroun (2012) yaptıkları çalışmada, Güney Afrika Johannesburg Borsa'sında yer alan 10 tane şirketin yayınlamış oldukları entegre raporları incelemişler ve aynı sektörde yer alan şirketlerin çevresel, sosyal ve 
şeffaflık konuları ile ilgili bilgilerinin birbirlerinden farklı olarak açıklandığını ortaya koymuşlardır.

Deloitte (2014) ise Hollanda Borsası'nda işlem gören 30 farklı sektördeki işletmenin son üç yıllık raporlarını incelediği çalışmada, entegre raporun Hollanda'da benimsenmeye devam ettiğini fakat açıklanan bilgiler arasında kopukluk bulunduğunu ifade etmiştir. Aynı şekilde Aydın (2015) tarafından yapılan bir diğer araştırmada BİST 100'de işlem gören işletmelerin 2012 ve 2013 yıllarına ait faaliyet raporlarını entegre raporlama ilkeleri ile uyumlarını incelemiş ve incelemenin sonucunda entegre raporlama uyum düzeylerinin yıllar itibari ile farklılıklar olduğunu açıklamıştır. Ercan ve Kestane (2017) ise yaptıkları çalışmada Türkiye' de yayınlanmış olan entegre raporların içerik analizini yapmışlar ve aynı sektörde faaliyet gösteren işletmelerde dahi değer yaratma bakımından farklılıklar olduğunu ifade etmiştirler.

Benzer şekilde PWC (2014b)'e Almanya Frankfurt Borsasına kote olan en büyük 30 işletmenin bulunduğu DAX 30 endeksine dahil olan işletmelerin yayımlamış oldukları entegre raporlar incelenmiş ve yayımlanan raporların sadece \%3' ünün entegre raporlamaya uygun olduğunu, \%13'ünün finansal olmayan bilgilerin yer aldığı fakat birleşik rapor formatında olduğunu ve \%77'sinin de finansal raporlar ve yönetim raporlarını içeren raporlar olduğunu tespit etmiştir. Benzer bir şekilde Hao (2014) ise, entegre raporun Kanada'daki durumu ve uygulanabilirliğini tespit etmeye çalışmış ve Kanada iş dünyasının entegre raporlama hazırlamaya hazır olmadığını ifade etmiştir.

K1lıç (2018), entegre rapor hazırlayan işletmelerin entegre raporlama performansını ve entegre raporlama hazırlamayan işletmelerin ise faaliyet raporlarının IIRC Entegre Raporlama Çerçevesi'nin belirlediği kılavuz ilkeler ve içerik öğelerini ne derecede sağladıklarını araştırmıştır. Çalışmanın sonucunda ise işletmelerin açıkladıkları bilgilerin tam olarak entegre raporlamaya uygun olmadıklarını ancak gelecek için umutlu olduklarını tespit etmiştir.

Öte yandan entegre raporlama hazırlamanın gelecekte daha iyi olacağını öne süren çalışmalardan olan Kaya ve diğerleri (2016) uluslararası boyutta entegre rapor hakkında bir fikir elde etmek için 13 farklı ülkeden 13 işletmeye ait entegre raporlar kapsam ve içerik bakımından incelenmiş ve raporlar arasında benzer ve farklı yönler ortaya konularak ileriki yıllar için entegre rapor uygulanması için önerilerde bulunmuştur.

Gençoğlu ve Aytaç (2016) ise BİST Sürdürülebilirlik Endeksi'nde yer alan işletmelerin yıllık faaliyet raporlarını inceleyerek çevresel ve sosyal sürdürülebilirlik konusundaki önemini belirtmişlerdir. Benzer bir çalışmada Yüksel ve Aracı (2017a) tarafından yapılmıştır. Bu çalışmada BİST Kurumsal Yönetim Endeksi'nde yer alan işletmelerin 2014 yılına ait faaliyet raporlarının entegre raporlamaya yakınlığını incelemiş ve endekste yer alan işletmelerin $\% 48$ 'inin faaliyet raporlarının entegre rapora uygun olduğunu tespit etmişlerdir. 
Aynı şekilde KPMG (2015, 2016, 2017), ayrı ayrı olarak 2014, 2015 ve 2016 yıllarında entegre raporlama hazırlayan Japon işletmelerinin raporlarını incelemiştir. 2015 yılında yapılan çalışmaya 142 Japon işletmesi dahil edilmiş ve IIRC Çerçevesi ilkeleri ile genel olarak uyumlu olduğu ve entegre raporlamanın temel unsuru olan sermayeleri açıklayan raporlar araştırmaya katılan işletmelerin \%28'i olarak tespit edilmiştir. 2016 yılında yapılan çalışmaya bir önceki yıla ek olarak 63 işletme daha eklenerek entegre rapor hazırlayan toplam işletme sayısı 205 olmuş ve tamamı araştırmaya dahil edilmiştir. Araştırmanın sonucunda ise önceki yıla göre yapılan açıklamaların olumlu yönde arttığını ve önceki çalışmaya kıyasla sermaye öğelerinin yer aldığı raporların \%44'ünde yer aldığ1 açıklanmıştır. 2017 yılında ise yine aynı çalışma yapılmış ve çalışmaya 74 işletme daha eklenmiştir. Söz konusu çalışmaya katılan işletme sayısı 279'a yükselmesine rağmen sermaye öğelerini açıklama oranının bir önceki yıla göre değişmediği tespit edilmiştir.

Yukarıdaki çalışmalardan farklı olarak, Gökten (2016) çalışmasında, IIRC çerçevesine dayanarak entegre raporun nasıl yapılacağı konusunda uygulayıcılar için sistematik bir yol haritası önermiştir. Aynı şekilde Elmacı ve Sevim (2017) yaptıkları araştırmada dünya üzerinde entegre raporlama konusunda başarılı dört işletmenin raporlarını ele alarak içerik bakımından incelemiş ve Türkiye'de faaliyette bulunan büyük ölçekli işletmelere raporlama hususunda bir yol haritası oluşturmaya çalışmışlardır.

İçerik analizine dahil edilen araştırmalarda en çok dikkat çeken unsur hazırlanan raporların sayısının azlığıdır. Söz konusu bu kısıtla birlikte analizlere dahil edilen ülke sayılarının da az olması içerik çalışmaları için sorun oluşturabilmektedir. Ayrıca Türkiye'de yapılan çalışmalarda entegre rapor sayısının araştırmalara dahil edilemeyecek kadar az olmasından dolayı işletmelerin sürdürülebilirlik ve faaliyet raporları üzerinden entegre raporlama hazırlanma yetisi üzerine araştırmalar yapılmaktadır. Bu tür araştırmalar her ne kadar fikir sağlasa da oldukça eksik kalmaktadır. Bu yüzden gelecek çalışmaların hem ülke sayılarında hem de entegre rapor sayılarında artışa gidilerek yıllara göre karşılaştırılması yapılarak verimli çalışmalar yapılabilir.

\subsection{Esas Alınan Konuya Göre Yapılan Çalışmalar}

Entegre Raporun Faydalarını Araştıran Çalışmalar

Entegre raporların faydalarını araştıran çalışmalardan bazıları (Azam ve diğerleri, 2011; Serafeim 2015; Churet ve Eccles, 2014; Arslan ve Özkan, 2018), faydal1 olduğunu savunurken, bazıları (Maniora,2015) ise fayda sağlayamadığını savunmaktadır

Azam ve diğerleri (2011), pazarlama ve finans yöneticileri, ekonomi ve finansal analistler ve danışmanlardan oluşan 150 kişiye ulaşarak entegre raporlamanın faydasını ölçmüşlerdir. Çalışmanın sonucunda finansal ve finansal olmayan bilgilerin entegre edilmesinin paydaş güvenini, itibarını ve müşteri bağlılığını nasıl artıracağını açıklamışlardır. Bir diğer çalışmada ise Serafeim (2015), entegre 
raporlamayı benimseyen firmaların daha çok uzun vadeli yatırımcılar ile ilgili olduğunu açıklamıştır. Benzer bir şekilde Churet ve Eccles (2014) ise, entegre raporlamanın sürdürülebilirlik yönetiminin etkinliği üzerindeki olumlu etkinin uzun vadede firmanın değerini artıracağını açıklamıştır. Entegre rapor uygulayan işletmelerin durumunu anket yoluyla tespit etmeye çalışan Arslan ve Özkan (2018), BİST Sürdürülebilirlik Endeksi'nde yer alan 29 işletmeye anket uygulaması gerçekleştirmiştir. Yapılan çalışmanın sonucunda ise entegre rapora karşı işletmelerin ilgili oldukları ve fayda sağlayacaklarını düşündüklerini tespit etmişlerdir.

Yukarıdaki çalışmaların aksine Maniora (2015) işletmelerin finansal olmayan bağımsız raporlardan entegre raporlamaya geçiş yapması ekonomik ve sürdürülebilirlik performans açısından fayda sağlamayacağı görüşünü savunmuştur. Açıklamalardan da anlaşılacağı üzerine entegre raporun faydaları üzerine yapılan çalışmalar farklı sonuçların ortaya çıkmasına neden olmuştur.

Entegre raporun faydalarının tespiti üzerine yapılan çalışmalar incelendiğinde, entegre raporun kısa vadeden ziyade özellikle uzun vadede işletme performansına katkı sağladığı tespit edilmiştir. Söz konusu çalışmaların faydalarının daha doğru sonuçlar verebilmesi için örneklem büyüklüğünün artırılması ve tüm sektörlerde araştırılması gereklidir. Aynı şekilde tüm sektörlerde de çalışmalar yapıldıktan sonra sektörler arasında karşılaştırmalar yapılarak entegre raporun faydasının anlaşılması net bir şekilde ortaya konulabilir. Ayrıca entegre raporlama hazırlanması için bir yol haritasının olmaması işletmeleri kısa vadede faydalı bir rapor ortaya çıkarmakta zor duruma sokmaktadır. Bu yüzden işletmeler de yıllar boyunca deneme yanılma yoluyla menfaat sahiplerinin istekleri doğrultusunda bilgiler sunmaya çalışmaktadırlar. Bu nedenle uzun vadeli sonuçlara odaklanan daha fazla araştırmaya ihtiyaç duyulduğu aşikardır.

\section{Değer Yaratma Açısından Yapılan Çalışmalar}

Entegre raporlamayla ilgili bazı çalışmalarda (örneğin, Blcak Sun, 2014; Ighian, 2015; Baboukardos ve Rimmel, 2016) entegre raporun işletmenin değerine katkısı olduğunu, piyasada artı değer katacağını savunurken bazı yazarlar (Thomson, 2015; Perego, 2016) ise işletmelerin değer yaratma unsurunu tam olarak kavrayamadıklarını ve entegre raporlamanın sosyal ve çevresel konularda olumlu yönde bir değer artışı sağlamayacağını ileri sürmektedir.

Bahsedilen yazarlardan olan Black Sun (2014) IIRC Pilot Programında yer alan 66 işletme üzerinde 23 ifadeden oluşan anket çalışması yapmış ve çalışmanın sonucunda işletmelerin değer yaratma unsurunu net bir şekilde anladığını vurgulamış ve entegre rapor düzenleyen işletmelerin yeni yatırımcılara sahip olduklarını ifade etmiştir. Benzer bir şekilde Ighian (2015) işletmelerin finansal bilgilerinin yanında finansal olmayan bilgilerini de açıklamasının ardından piyasada bir güven artışı sağladığı ve bu sayede yatırımcı sayılarını artırdığı gözlemlenmiştir. Nitekim Baboukardos ve Rimmel (2016) entegre raporlamanın 
zorunlu olarak yayınlandığı Güney Afrika'da Johannesburg Borsası'na kayıtlı olan 954 işletme üzerinde araştırma yapmış ve araştırma sonucunda finansal olmayan bilgilerin paylaşılması firma değerini artırdığı tespit edilmiştir.

$\mathrm{Bu}$ araştırmaların aksine ise Perego (2016)'da entegre raporun uygulanması ile teorisi arasındaki farklılıkları incelediği araştırmada işletmelerin değer yaratma unsurunu tam olarak kavrayamadığını açıklamıştır.

Entegre rapor, finansal ve finansal olmayan bilgileri yatırımciların talepleri doğrultusunda güvenilir, doğru ve şeffaf şekilde açıklanması hem artı değer yaratmakta hem de rekabet avantajı sağladığı gözlemlenmektedir. Özellikle değer yaratma kavramı entegre raporlamanın hazırlanması zorunlu olan ülkelerde, zorunlu olmayan ülkelere kıyasla daha net şekilde görüldüğü söylenmektedir (Baboukardos ve Rimmel, 2016: 20).

\section{Entegre Raporlama ve Işsletme Performansına Etkisini İnceleyen Çalışmalar}

Entegre raporlamanın işletme performansına etkisini inceleyen çalışmalarda genellikle sözkonusu etkinin olumlu olduğu ileri sürülmektedir. Nitekim bunlardan birinde Bernardi ve Stark (2015), Güney Afrika'da 40 işletmenin 2008 ve 2012 yılları arasındaki 4 yıl boyunca açıklamış oldukları bilgileri inceleyerek entegre raporlama üzerindeki etkisini ölçmeye çalışmışlardır. Örneklemde yer alan işletmelerin çevresel, sosyal ve yönetimsel bilgilerinin yanında hisse başına fiyat, toplam varlıklar, toplam kaynaklar ve net kar bilgilerini incelemişlerdir. $\mathrm{Bu}$ incelemeler sonucunda entegre raporlama uygulayan bazı sektörlerde işletmelerin performanslarında artış olduğunu tespit etmişlerdir. Yine Aceituno ve diğerleri (2013) işletmeler ne kadar yüksek kar elde ederlerse bu bilgileri açılamak adına daha fazla gönüllü olduklarını ifade etmiștir.

Bir diğer çalışmada ise Barth ve diğerleri (2015) Güney Afrika Menkul Kıymetler Borsasında 2011-2013 yılları arasında entegre raporlama düzenleyen 224 işletmeyi incelemiştir. İncelemenin sonucunda entegre raporlama kalitesinin firma değeri (Tobin Q) ve gelecekte beklenen nakit akışı ile pozitif bir ilişki olduğu sonucuna ulaşmışlardır.

Turturea (2015) ise Danimarka'da sağlik sektöründe hizmet veren Novo Nordisk işletmesinin finansal performansı ve hisse fiyatı üzerinde entegre rapor hazırlamanın etkisini araştırmıştır. Araştırmanın sonucunda ise 1993 - 2003 yılları arasında işletmenin hazırlamış olduğu sosyal sorumluluk raporları işletmenin finansal performansına ve hisse senedi fiyatına etki yapmadığı ancak 2004 - 2014 yılları arasında yayınlamış olan entegre raporları işletmenin finansal performansı ve hisse senedi fiyatı üzerinde pozitif etki oluşturdu sonucuna ulaşmıştır.

Genellikle işletmelerin performansları değerlendirilirken karlılık göstergesi kullanılmaktadır. Ancak karlılık göstergesini tek başına kullanmak yetersiz olmaktadır. İşletmeler performansı çok boyutlu bir şekilde değerlendirmeleri gereklidir. Karlılık, kalite, maliyet, müşteri ve çalışan memnuniyeti, hisse başına 
kazanç, yenilik, büyüme vb. gibi doğrudan veya dolaylı bir şekilde kullanılan göstergelerin de araştırmalara dahil edilmesi uygun olacaktır. Araştırmacıların benzer sonuçlar bulması örgütsel karmaşıklığın ve dış finansman ihtiyacının bu ilişkiyi güçlendirdiği söylenebilir.

\section{Sonuç}

İşletmeler finansal bilgilerinin yanı sıra finansal olmayan bilgilerini de açıklayarak faaliyetlerinin şeffaflığını sağlarken, diğer bir yandan da doğa ve toplum üzerindeki etkilerini göstermiş olacaklardır. İşletmeler tüm bu etkileri sadece geçmişe yönelik değil aynı zamanda geleceğe yönelik hazırlayarak belirleyecekleri risk ve firsatları, yönetim yaklaşımlarını ve stratejilerini de belirterek karar alıcılar ile aradaki güvensizliği makul bir güvenceye indirmeye çalışacaklardır.

İlgili literatür incelendiğinde, yurt dışı yapılan çalışmalarda, söz konusu raporlarda açıklanan bilgiler arasında kopukluklar olması (Deloitte, 2014), bazı ülkelerde yayımlanan raporlarda alt yapı eksikliği (Hao, 2014), tam bir entegre raporun hazırlanmasının uzun süre alması (Havlova, 2015), kamu personellerinin entegre raporlama konusunda isteksiz olmaları (Chersan, 2015) gibi nedenlerden dolay1 işletmelerin kullanabilecekleri kılavuz bir entegre raporun olmadığı sonucu ortaya çıkmaktadır. Nitekim PWC (2014b) Almanya gibi gelişmiş bir ülkede hazırlanan raporların \%3'ünün uygun olduğunu ileri sürmektedir. Bu görüş işletmeler için uygun entegre rapor formatının oluşmadığı düşüncesini desteklemektedir. Aynı şekilde Türkiye'de yapılan çalışmalardan işletmelerin düzenledikleri entegre raporların yıllar itibariyle uyumlu olmadıkları (Aydın, 2015), bazı çalışmalarda entegre raporlama konusunda yol haritası oluşturma çalışmaları (Örneğin, Gökten, 2016; Elmacı ve Selim, 2017) Türkiye'de de entegre raporun hazırlanması ve sunumuna ilişkin kılavuz bir rapor olmadığı sonucunu doğurmaktadır. Bu sebeple hazırlanan entegre raporlar çeşitli sonuçlar doğurmaktadır. Bu görüşler çerçevesinde yatırımcıların bir işletmenin kontrol sistemine dahil olma konusunda sağlıklı bilgi edinmesi oldukça zor görünmektedir. Ancak bu çalışmaların aksine, entegre raporların günden güne daha geliştiğini, içeriğinin entegre raporlama çerçevesine yaklaştığını ve faydalarının arttığı da söylenebilmektedir (Chersan, 2015; KPMG, 2017; Yüksek ve Arac1, 2017a; Kılıç 2018).

Entegre raporlamanın genel bir çerçevesi olmasına rağmen ülkeden ülkeye, sektörden sektöre ve işletmeden işletmeye farklılıkların olması ve en iyi entegre rapor şeklini işletmelerin kendilerinin deneme yanılma yoluyla bulmalarının sebebi hazırlanan raporun kural bazlı değil ilke bazlı olmasından kaynaklandığ düşünülmektedir. Söz konusu raporların ilke bazlı hazırlanması entegre raporların faydalarını, karşılaştırılabilirliğini ve denetimini zorlaştırsa da değer yaratma açısından daha faydalı olacağı düşünülmektedir. Nitekim entegre raporların zorunlu olarak hazırlandığı ülkelerde değer yaratma kavramının daha iyi anlaşıldığı görülmektedir. Ayrıca, işletmelerin hazırlamış oldukları entegre raporlar IIRC çerçevesi ilke ve içerik öğelerine benzer şekilde hazırlanıyor olsa da işletmelerin yaşadığı en büyük sıkıntılardan birisi kısalık ilkesidir. Çünkü entegre raporun neye 
ve kime göre kısa olacağı açık ve net şekilde bilinmemektedir. Bu hususla ilgili bazı işletmelerin entegre raporu stratejik öykü ve beklenti aracı olarak görmesi (Higgins ve diğerleri, 2014), işletmenin kurumsal meşruiyetini ve itibarını artırmak için benimsemesi (Steyn, 2014) aynı zamanda raporun uzun olmasina da neden olmaktadır. Söz konusu raporda hem finansal hem de finansal olmayan bilgilere aynı anda yer veriliyor olması raporun kısa hazırlanmasını oldukça zorlaştırmaktadır.

İlgili literatür incelendiğinde entegre raporun denetimine ait önerilerin olduğu çalışmalara rastlanılmamıştır. Finansal olmayan bilgilerin güvenilirliğini ölçmede kullanılan AA1000 Güvence Standardı mevcut olsa da hem finansal hem de finansal olmayan bilgilerin güvenilirliğini sağlayacak bir standart geliştirilmesi gereklidir. $\mathrm{Bu}$ doğrultuda yapılacak akademik çalışmaların artması da standart koyucular için teşvik niteliğinde olabilir.

Günümüzde halen gelişimine devam eden entegre raporlama konusunda belirsizlikler ve eksiklikler hala mevcut olmakla birlikte gelecekte yapilacak akademik çalışmalarla birlikte, uluslararası kuruluşların desteği ve işletmelerin de verecekleri doğru tepkilerle entegre raporlama hak ettiği yeri bulacaktır. Birçok ülkede muhasebe eğitimi hala finansal raporlama ve temelindeki düzenlemelere dayanmaktadır. Özellikle lisansüstü öğrenciler finansal olmayan raporlara ve bunun dallarına aşina değillerdir. $\mathrm{Bu}$ nedenle gelecekte entegre raporlama ile ilgili çalışmaların kalite, nitelik ve nicelik yönünden artması için muhasebe eğitimi içerisine finansal olmayan bilgilerin nasıl raporlanacağı hususunun da dahil edilmesi gereklidir. Bununla birlikte entegre raporun disiplinler arası (muhasebe finans, kurumsal yönetim, yönetim ve organizasyon gibi), politikacılar ve toplum ile bir bağın oluşturulması, farkındalığın yaratılması geleceğe 1şık tutacaktır.

\section{Kaynakça}

Abeysekera, I. (2013). A Template For Integrated Reporting. Journal of Intellectual Capital, 14(2), 227-245.

Aceituno, J. V., Rodriquez, A. L. Ve Garcia-Sanchez, I. M. (2013). Is integrated reporting determined by a country's legal system? An exploratory study. Journal of Cleaner Production, (44), 45-55.

Arslan, M. ve Özkan, O. (2018). Entegre Raporlamaya Evrilme Süreci ve Durum Tespiti-Bist Örneği. Mali Çözum Dergisi/Financial Analysis, (148), 29-52.

Atkins, J. ve Maroun, W. (2015). Integrated Reporting in South Africa in 2012: Perspectives From South African Institutional Investors. Meditari Accountancy Research, 23(2), 197-221.

Aydın, S. (2015). Entegre Raporlama, İstanbul: Türkmen Kitapevi. 
Azam, Z., Warraich, K. M. ve Awan, S. H. (2011). One report: Bringing change in corporate reporting through integration of financial and non-financial performance disclosure. International Journal of Accounting and Financial Reporting, 1(1), 50-71.

Baboukardos, D. ve Rimmel, G. (2016). Value relevance of accounting information under an integrated reporting approach: A research note. Journal of Accounting and Public Policy, 35(4), 437-452.

Barth, M. E., Cahan, S. F., Chen, L., ve Venter, E. R. (2016). The economic consequences associated with integrated report quality: early evidence from a mandatory setting. University of Pretoria, unpublished working paper, 1-45.

Bernardi, C. ve Stark, A. W. (2016). Environmental, social and governance disclosure, integrated reporting, and the accuracy of analyst forecasts. The British Accounting Review, 50(1), 16-31.

Black Sun, PLC. (2014). Realizing the benefits: the impact of integrated reporting. http://integratedreporting.org/wp-content/uploads/2014/09/IIRC. Black_. Sun_. Research. IR_(Erişim: 12.04.2018)

Chersan, I. C. (2015). Study On Practices And Tendencies in Integrated Reporting. Audit Financiar, 13(129), 91-101.

Churet, C. ve Eccles, R. G. (2014). Integrated reporting, quality of management, and financial performance. Journal of Applied Corporate Finance, 26(1), 5664.

Deloitte. (2014). Integrated Reporting in the Netherlands: the Journey Continues and is Gaining Traction and Pace. https://integratedreporting.org/resource/deloitte-integrated-reporting-in-thenetherlands/ (Erişim: 03.03.2018)

Dereköy, F. (2018). Entegre Raporlama Uygulamalarının Uluslararası Entegre Raporlama Çerçevesi Bağlamında Değerlendirilmesi, Journal of Administrative Sciences/Yonetim Bilimleri Dergisi, 16(32), 589-608.

DeVilliers, C., Venter, E. R. ve Hsiao, P. C. K. (2016). Integrated Reporting: Background, Measurement Issues, Approaches and an Agenda For Future Research. Accounting ve Finance, 57(4), 937-959.

Eccles, R. G. ve Armbrester, K. (2011). Integrated Reporting in the Cloud. IESE Insight, First Quarter (8), 13-21.

Eccles, R. G. ve Saltzman, D. (2011). Achieving sustainability through integrated reporting. Stanford Social Innovation Review, 59, 56-61.

ERTA. (2018). http://entegreraporlamatr.org/tr/hakkimizda/biz-kimiz.aspx (Erişim: 08.05.2018) 
Elmac1, O. ve Sevim, Ş. (2017). Entegre Raporlamada Küresel Gelişmeler ve Türkiye İçin Bir Model Önerisi. Uluslararası Sosyal ve Eğitim Bilimleri Dergisi, 4(8), 18-36.

Ercan, C. ve Kestane, A. (2017). Entegre Raporlama Ve Türkiye'deki Uygulama Örnekleri Üzerine Bir Araştırma. Kırklareli Üniversitesi İktisadi Ve İdari Bilimler Fakültesi Dergisi, 6(4), 73-86.

Gençoğlu, Ü. G. ve Aytaç, A. (2016). Kurumsal Sürdürülebilirlik Açısından Entegre Raporlamanın Önemi ve BIST Uygulamaları. Muhasebe ve Finansman Dergisi, (72), 51-66.

Global Reporting Initiative-GRI (2014). Raporlama İlkeleri ve Standart Bildirimler, https:// www.globalreporting.org/resourcelibrary/Turkish-G4-PartOne.pdf (Erişim: 10.04.2018)

Gökten, S. (2016). Entegre Raporlama Yaklaşımı İçin Uygulamaya Yönelik Sistematik Bir Öneri. Muhasebe Bilim Dünyası Dergisi, 18(4), 741-765.

Havlova, K. (2015). What integrated reporting changed: the case study of early adopters. Procedia Economics and Finance, 34, 231-237.

Higgins, C. Stubbs, W. ve Love, T. (2014). Walking the talk(s): Organisational narratives of integrated reporting. Accounting, Auditing and Accountability Journal, 27(7), 1090-1119.

Ighian, C. D. S. (2015). Integrated Reportıng--The Future Of Financial Reportıng. Internal Auditing and Risk Management, 10(2), 125-134.

International Integrated Reporting Council - IIRC (2013). Uluslararas1 Entegre Raporlama Çerçevesi, http://integratedreporting.org/wpcontent/uploads/2015/03/13-12-08THE -INTERNATIONAL-IRFRAMEWORK-Turkish.pdf (Erişim: 19.03.2018)

Integrated Reporting Council of South Africa - IRCSA (2011). Framework for Integrated Reporting and the Integrated Report: Discussion Paper, http://www.sustainabilitysa.org/Portals/0/IRC\%20of\%20SA\%20Integrated\%2 0Reporting\%20Guide\%20Jan\%2011.pdf (Erişim: 02.03.2018)

Kılıç, B. I. (2016). Entegre Raporlama ve Türkiye'deki Gelişmeler: Entegre Rapor Hazırlayan İşletmeler ve Bist Kurumsal Sürdürülebilirlik Endeksinde Yer Alan İşletmeler Açısından Bir İnceleme. Muhasebe Bilim Dünyası Dergisi, 20(1), 2864.

KPMG. (2015). Survey of Integrated Report in Japan 2014. https://home.kpmg/content/dam/kpmg/pdf/2015/09/integrated-reporting20150628e.pdf (Erişim: 13.04.2018) 
KPMG. (2016). Survey of Integrated Report in Japan 2015. https://assets.kpmg/content/dam/kpmg/pdf/2016/05/jp-en-integrated-reporting20160426.pdf (Erişim: 13.04.2018)

KPMG. (2017). Survey of Integrated Report in Japan 2016. https://assets.kpmg/content/dam/kpmg/xx/pdf/2017/06/survey-of-integratedreports-in-japan-2016.pdf (Erişim: 14.04.2018)

Katsikas, E., Manes Rossi, F. ve Orelli, R. L. (2016). Towards Integrated Reporting: Accounting Change in the Public Sector, Cham: Springer.

Kaya, Uğur ve diğerleri (2016). Yeni Bir Kurumsal Raporlama Yaklaşımı Olarak Entegre Raporlama ve Dünyadaki Uygulama Örnekleri Üzerine Bir Araştırma. Karadeniz Teknik Üniversitesi Sosyal Bilimler Enstitüsü Sosyal Bilimler Dergisi, 6(11), 85-101.

Lapteş, R. ve Sofian, I. (2016). A New Dimension of The Entities' Financial Reporting: Integrated Reporting. Bulletin of the Transilvania University of Braşov. Series V: Economic Sciences, 9(2), 239-250.

Maniora, J. (2015). Is integrated reporting really the superior mechanism for the integration of ethics into the core business model? An empirical analysis. Journal of business ethics, 140(4), 755-786.

Perego, P., Kennedy, S. ve Whiteman, G. (2016). A lot of icing but little cake? Taking integrated reporting forward. Journal of cleaner production, (136), 5364.

PWC (2013). A Benchmark Study of Swedish Large Cap Copmanies' Reporting 2012. https://www.yumpu.com/en/document/read/40679626/a-benchmarkstudy-of-swedish-large-cap-companies-pwc (Erişim: 18.04.2018)

PWC (2014a). Integrated Reporting: Spanish Companies Show Progress But Still Lag Behind Some of their European Peers. http://www.pwc.com/gx/en/auditservices/corporatereporting/publications/wor d-watch/articles/spain-integratedreporting-ibex35.jhtml (Erişim: 21.03.2018)

PWC (2014b). Integrated Reporting in Germany: The DAX 30 Benchmark Survey. https://www.pwc.de/de/rechnungslegung/assets/studie-integrated-reporting2015.pdf (Erişim: 14.03.2018)

PWC (2015). Integrated Reporting in Malaysia-An Analysis of the Reporting by Bursa Malaysia's Top 50 Companies. http://read.pwc.com/i/567317-inspiringtrust-throughtinsight-integrated-reporting-in-malaysia (Erişim: 15.02.2018)

Rowbottom, N. ve Locke, J. (2016). The Emergence of $\langle\mathrm{IR}\rangle$. Accounting and Business Research, 46(1), 83-115.

Serafeim, G. (2015). Integrated reporting and investor clientele. Journal of Applied Corporate Finance, 27(2), 34-51. 
Solomon, J. ve Maroun, W. (2012). Integrated Reporting: The Influence of King III on Social, Ethical and Environmental Reporting. The Association of Chartered Certified Accountants (ACCA), 1-56.

Steyn, M. (2014). Organisational Benefits and Implementation Challenges of Mandatory Integrated Reporting: Perspectives of Senior Executives at South African Listed Companies. Sustainability Accounting, Management and Policy Journal, 5(4), 476-503.

Stubbs, W., Higgins, C., Milne, M. J. ve Hems, L. (2014). Financial capital providers' perceptions of integrated reporting. Financial Capital Providers' Perceptions of Integrated Reporting Working Paper, 1-17.

Surty, M., Yasseen, Y. ve Padia, N. (2018). Trends in integrated reporting: a stateowned company analysis. Southern African Business Review, 22(1), 1-22.

Thomson, I. (2015). But does sustainability need capitalism or an integrated report'a commentary on 'The International Integrated Reporting Council: A story of failure'by Flower, J. Critical Perspectives on Accounting, 27, 18-22.

Turturea, M. (2015). Integrated Reportıng Into Practice-A Ten Year Experience. SEA: Practical Application of Science, 3(1), 565-572.

Topçu, M. K. ve Korkmaz, G. (2015). Entegre Raporlama: Kavramsal Bir İnceleme. Dokuz Eylül Üniversitesi İktisadi ve İdari Bilimler Fakültesi Dergisi, 30(1), 1-22.

Yüksel, F. ve Aracı, H. (2017a). Entegre Raporlama, Türk İşletmelerinin Entegre Raporlamaya Bakışı Üzerine Bir Araştırma. Yönetim ve Ekonomi, 24(3), 741757.

Yüksel, F. ve Aracı, H. (2017b). Hizmet İşletmelerine Ait Raporların Entegre Raporlama İlkeleri Açısından İncelenmesi. Uluslararası İktisadi ve İdari Incelemeler Dergisi, 16(UİK Özel Sayıs1), 729-748. 